\title{
Improving the Efficiency of Turning Processing of Heat- Resistant Alloys by Introducing Ultrasonic Field Energy into the Cutting Zone
}

\author{
Aleksandr Khramov ${ }^{1, a}$, Maksim Gorchcov ${ }^{1, b}$, Nguyen Khan Toan ${ }^{2,3, c}$ and \\ Evgeniy Kiselev3,d \\ 1GK "HALTEC", Ulyanovsk, street Narimanova, 1,b,Russian Federation
}

${ }^{2}$ Hyngien University of Education and Technology, Hanoi, Socialist Republic of Vietnam

${ }^{3}$ Ulyanovsk State Technical University, Ulyanovsk, street Nord Venec,32, Russia Federation

aalexander_khramov@haltec.ru, bmaksim_gorshkov@haltec.ru, cNguyen_Khan_Toan@gmail.com, ${ }^{\mathrm{d}} \mathrm{kec} . u l s t u @ m a i l . r u$

Keywords: Turning, Heat-Resistant Alloys, Cutting Zone, Cutting Tool, Ultrasonic Energy

\begin{abstract}
Studies have been carried out to assess the effectiveness of dry processing by the current preparations from the heat-resistant alloy CN45MVTUBR with mineral ceramic incisors with the introduction of the ultrasound-field energy treatment zone. It has been established that the use of ULTRASOUND in the rough treatment of mineral ceramic tools without coolant allows to reduce the depth of the defective layer in 1.5 times.
\end{abstract}

A feature of modern machining production is the need to manufacture an ever-increasing number of complex and non-rigid, thin-walled parts in various machines and mechanisms, primarily in aircraft. The latter is explained, on the one hand, by an increase in the speeds of their executive movements (and, consequently, by the desire to reduce inertial loads), and on the other, by the removal of almost complete previous restrictions on designers in creating complex parts due to the existing technological capabilities of modern 3-5 axial machines and CNC machining centers. One more thing can be added to this: a decrease in structural rigidity, as a rule, is accompanied by the simultaneous use of high-strength and, therefore, hard-to-work steels and alloys as structural materials to maintain the necessary strength while reducing the cross sections of manufactured parts. A feature of modern machining production is the need to manufacture an ever-increasing number of complex and non-rigid, thin-walled parts in various machines and mechanisms, primarily in aircraft. The latter is explained, on the one hand, by an increase in the speeds of their executive movements (and, consequently, by the desire to reduce inertial loads), and on the other, by the removal of almost complete previous restrictions on designers in creating complex parts due to the existing technological capabilities of modern 3-5 axial machines and CNC machining centers. One more thing can be added to this: a decrease in structural rigidity, as a rule, is accompanied by the simultaneous use of high-strength and, therefore, hard-to-work steels and alloys as structural materials to maintain the necessary strength while reducing the cross sections of manufactured parts.

As materials for such parts, hard-to-work corrosion-resistant and heat-resistant steels are used, as well as alloys based on titanium and nickel. Thus, the share of titanium and heat-resistant alloys in the design of fourth-generation aircraft engines for the year was about 89\% [1], in the fifthgeneration engines this percentage is even higher. The problem of ensuring the specified

(c) (1) Content from this work may be used under the terms of the Creative Commons Attribution 3.0 license. Any further distribution of this work must maintain attribution to the author(s) and the title of the work, journal citation and DOI. Published under license by Materials Research Forum LLC. 
operational properties in the manufacture of non-rigid parts from difficult-to-process materials, in which residual stresses of any sign arising due to heat-stress and structural-phase transformations can cause significant changes in shape and spatial orientation, is much more acute than for other structural materials. This is due to the fact that their heat and temperature conductivity is 4-5 times less than that of structural carbon steels and all the heat that occurs in the cutting zone is localized in the surface layer (SL) of the workpiece being processed.

In practice, this translates into the need to significantly reduce the elements of the cutting condition, and in some cases, even the need for empirical selection of the manufacturing sequence. The machining of workpieces of parts with complex spatial shapes is most often carried out at expensive machining centers for which such performance losses are unacceptable. It is obvious that a high-performance removal of stocks from blanks from any structural materials is accompanied by a high heat-power intensity of the processing process. This leads to the appearance in SL of preforms from difficult to process materials of significant technological residual stresses (TRS), the negative impact of which on the operational characteristics of manufactured parts is well known.

Traditional technologies for processing workpieces made of heat-resistant alloys belonging to the category of difficult to work, do not allow to achieve high values of the cutting condition elements (cutting speed, feed). This is due to their physico-mechanical properties, such as high hardening of the material during deformation by cutting, the ability of the material to maintain its original strength and hardness at high temperatures arising in the cutting zone, low thermal conductivity, which contributes to insufficient heat removal from the contact zone of the tool and the workpiece, as well as the presence of intermetallic or carbide inclusions in their composition, leading to abrasive wear of the tool cutting edge.

The most efficient processing of workpieces made of heat-resistant nickel-based alloys can be carried out with a tool made of such a material, which is characterized by high cutting properties, such as high values of red resistance, stability of cutting properties over a wide temperature range and resistance to abrasive wear. Carbide tools currently used as tool materials do not possess the required characteristics.

The low machinability of heat-resistant alloys is determined by their physical and mechanical properties. In these conditions, it is very necessary to disclose the reasons affecting their machinability, and to find ways and means to increase the productivity of their processing on metal cutting machines.

The basic structure of most heat-resistant alloys is usually an austenitic-grade solid solution with a face-centered cubic lattice. Moreover, most of the deformable heat-resistant alloys belong to the type of dispersion hardening, i.e.in these alloys, a structural component is released from the solid solution - the second phase, which is different from its base and is dispersed throughout the alloy in finely divided form.

High dispersion of the structure prevents the occurrence and development of slip processes, while the creep resistance of the alloy increases.

Heat-resistant nickel-based alloys are characterized by a significant loss of strength and facilitation of the cutting process at temperatures above 800 degrees C. [2]. Earlier experiments at HALTEC Group found that the processing efficiency of workpieces made of heat-resistant nickelbased alloys can be increased by replacing conventional cutting tools with SSY ceramic tools (30 times more productivity compared to using carbide tools) with a simultaneous increase in speed cutting up to 600 and more $\mathrm{m} / \mathrm{min}$ (fig. 1) [3]. 
The project solution. Equipment. Technology. The tool. Snap-in.

\section{Ceramic tools in Aviation}
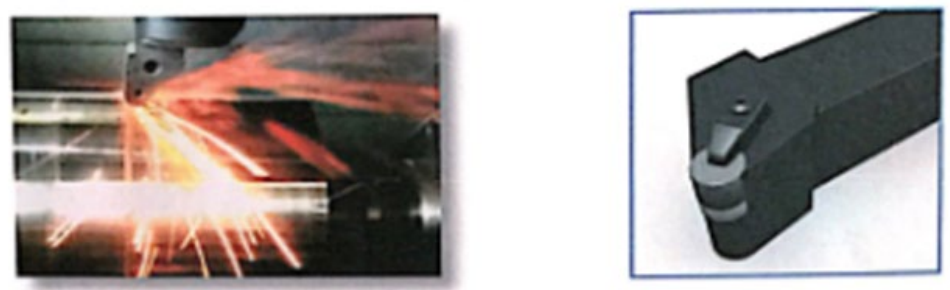

Turning of heat-resistant nickel-based alloys using ceramic plates.

The material of the workpiece - Inconel 718

MAZAK - INTEGREX $i$-200 machine

Qmin (cm3/min) performance

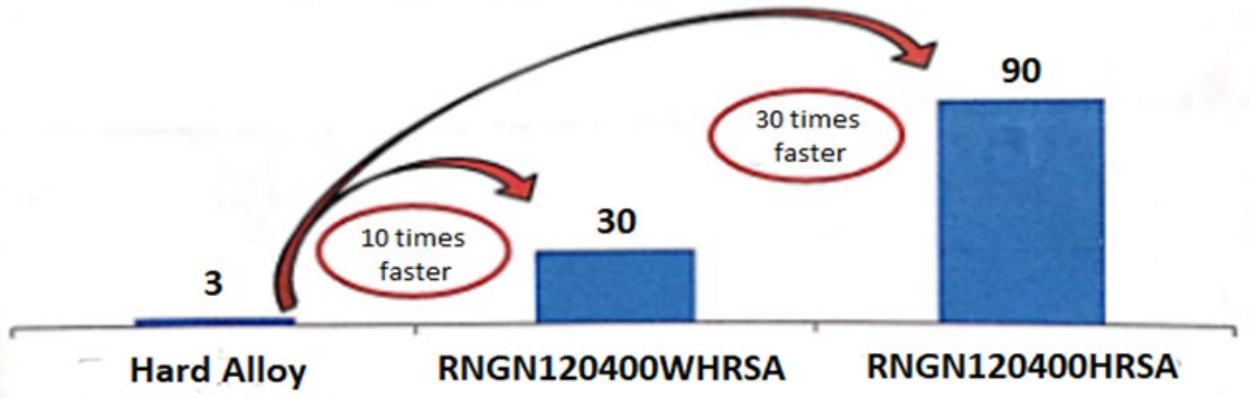

\begin{tabular}{|c|c|c|}
\hline Carbide plate & $\begin{array}{c}\text { Ceramic plate } \\
\text { RNGN120400WHRSA }\end{array}$ & $\begin{array}{c}\text { Ceramic plate } \\
\text { RNGN120400HRSA }\end{array}$ \\
\hline Lubricating and cooling liquid & Lubricating and cooling liquid & Air blowing \\
Ap=1,5 mm & Ap=1,5 mm & Ap=1,5 mm \\
$V=20 \mathrm{~m} / \mathrm{min}$ & $\mathrm{V}=200 \mathrm{~m} / \mathrm{min}$ & $\mathrm{V}=600 \mathrm{~m} / \mathrm{min}$ \\
$(\mathrm{n}=32 \mathrm{rpm})$ & $(\mathrm{n}=318 \mathrm{rpm})$ & $(\mathrm{n}=955 \mathrm{rpm})$ \\
$\mathrm{F}=3 \mathrm{~mm} / \mathrm{min}$ & $\mathrm{F}=32 \mathrm{~mm} / \mathrm{min}$ & $\mathrm{F}=96 \mathrm{~mm} / \mathrm{min}$ \\
$(\mathrm{f}=0,1 \mathrm{~mm} / \mathrm{rev})$ & $(\mathrm{f}=0,1 \mathrm{~mm} / \mathrm{rev})$ & \\
& & \\
& & \\
& & \\
& & \\
& & \\
& & \\
\end{tabular}

The SSY ceramic tool showed a 30 -fold increase in performance relative to the carbide!

Fig.1. Results of pilot tests of new types of mineralokeramika at the production site of HALTEK Group of Companies

The latter is explained by high values of contact temperature (800-850 degrees Celsius), which leads to the implementation of the process of forming new surfaces under thermoplastic conditions. Such processing is accompanied by a significant decrease in cutting forces, which explains the 
reasons for the sharp increase in the productivity of stock removal. Obviously, this method can be used only during preliminary (rough) processing, since high contact temperatures in the cutting zone will inevitably cause the appearance of a defective layer. Further research by HALTEC employees and industrial testing at a number of aircraft engine companies established the high efficiency of cermet tools for rough milling and turning of billets made of heat-resistant alloys without cutting fluid (coolant). However, tests at the Rybinsk Motor-Building Association established the depth of the defective layer at (0.2-0.3) $\mathrm{mm}$. This is unacceptable for final machined parts, increases the duration of semi-finishing and final processing and is unacceptable in the manufacture of thin-walled non-rigid parts.

Further intensification of the machining processes by cutting, reducing the depth of propagation of TRS and reducing the likelihood of other defects in the SL of the machined parts can be carried out by external energy influences on the contacting objects [4]. At the same time, this will facilitate the process of forming new surfaces by reducing the cost of dislocation movement, provide a reduction in cutting force, but also reduce contact temperatures. It can reduce the depth of the defective layer. However, the latter, on the contrary, can complicate the processes of shaping. This will inevitably lead to a decrease in the productivity of stock removal, but can reduce the depth of the defective layer of manufactured parts.

From the large number of types, forms and patterns of energy effects on the cutting process [5], the most simple and economical is the introduction of the energy of an ultrasonic (ultrasonic) field into the contact zone. Considering that the introduction of ultrasonic vibrations helps to reduce frictional processes, and hence contact temperatures, the feasibility of such an effect when processing billets of heat-resistant alloys with ceramic tools requires experimental confirmation.

The result of numerous studies performed in various countries was the possibility of practical implementation of dimensional machining with ultrasonic testing by using special devices and installations for applying the energy of the ultrasonic field to the workpiece (tool, coolant, machine parts and tooling, etc.) [5-7]. At present, DMG MORI has developed and mass-produced a line of 18 models of the ULTRASONIC series machines, in which a device for superimposing ultrasonic cutting on the cutting tool is integrated in the design of the spindle unit. AXILE Machining machines are similar. At the same time, ultrasonic mandrels (Altrasonic, CRENO Industry, Pulchertool companies) are commercially available, the use of which is permissible on CNC machined centers equipped with spindles with ISO40 cone (SK40, BT40) [8]. Under these conditions, it is extremely important to identify the possibility of reducing contact temperatures without reducing the intensity of stock removal by introducing the ultrasonic field energy into the contact zone of the cutting tool and suggest new effective means of reducing the cost of manufacturing complex non-rigid parts from heat-resistant chromium-nickel alloys.

During the research, preliminary results were obtained on evaluating the efficiency of turning blanks from the heat-resistant CN45MVTUBR alloy (analog of the Inconel 718 alloy) dry (air cooling) with RNGN120400HRSA mineral ceramics cutters SSY series (South Korea) with the introduction of ultrasonic field energy into the processing zone. The experiments were performed on a Quantum Opti D420x 1000 DPA screw-cutting lathe. During the processing, the components of the cutting force Pz, Py, Px and the torque $\mathrm{M}$ cr. were measured using a UDM-600 dynamometer equipped with Kyowa kfg-5-120-c1-11 strain gages. In addition, using the TemPro$1200 / 1600 / 2200$ thermal imager-pyrometer, the temperature on the front surface of the ceramicmineral plate was monitored as close as possible to the contact zone with the workpiece. In the first series, workpieces were processed without introducing ultrasonic vibrations into the shaping zone, in the second, ultrasonic testing from an ultrasonic generator UZG 641 A was applied to the 
cutting tool, with a frequency $\mathrm{f}=18.6 \mathrm{kHz}$ and an amplitude $\mathrm{A}=10 \mu \mathrm{m}$. In both series, elements of the cutting condition were used: cutting depth $\mathrm{t}=1.5 \mathrm{~mm}$, feed $\mathrm{S}=0.1 \mathrm{~mm} / \mathrm{rev}$, cutting speed $\mathrm{V}=600 \mathrm{~m} / \mathrm{min}$.

The introduction of the energy of ultrasonic vibrations into the shaping zone, according to the authors, can change the nature of the movement of dislocations in the shaping zone and reduce the size of the defective layer. To verify this assumption, before and after processing, the samples for research were evaluated by the non-destructive method of phase transformations in the surface layer of metals and alloys on the RIKOR-7 X-ray measuring complex and technological residual stresses of the first kind on the SITON ARM device.

As the analysis of research results shows, the assumptions made are fully confirmed. The introduction of the energy of ultrasonic vibrations into the turning zone reduces the contact temperature on the front surface of the cutter by (12-17) \%, however, no reduction in processing productivity (estimated by the cutting force components) was observed. The control of the quality parameters showed that the depth of the defective layer (evaluated by the magnitude and depth of propagation of the technological residual stresses and phase changes) decreased in 1.45 times.

Thus, the performed studies have proved the feasibility of introducing ultrasound field energy into the turning zone of billets from heat-resistant alloys.

\section{References}

[1] A.Y. Kachan, V.F. Mozgovoy, S.B. Belikov: Main directions of technology development and metal cutting machines with CNC In:Visnik of dwigunobuding. 2007 №2, pp. 82-85.

[2] Kiselyov E.S.: Modern ultrasonic dimensional technologies of mechanical processing of hard-to-process and composite materials. In: Science-intensive technologies in mechanical engineering 2020. № 9, pp. 33-39. https://doi.org/10.30987/2223-4608-2020-9-33-39

[3] Kiselev E.S., Blagovskiy O.V. Management of the formation of residual stresses in the manufacture of critical / parts: monograph..- St. Petersburg: Lan, 2020, $140 \mathrm{p}$

[4] Kumabe D.: Vibrational cutting. Translation from yap. S.L. Maslennikova. Edited by I.I. Portnova and V.V. Belov. M.: Mechanical Engineering (1985).

[5] Mikhailov A.N.: Basics of synthesis of functionally oriented technologies. Donetsk: DonNTU (2009).

[6] Nguen Han Toan, Kiselyov E.S.: Heatproof Relaxation of Welding Stresses Openwork Designs of Large Size Ultrasonic Field. Solid State Phenomena. In: Vol. 303 (05). 2020, pp 124131 (2020). https://doi.org/10.4028/www.scientific.net/SSP.303.104

[7] Nazarov M. V., Savelev K. S. and Kiselev E. S. .Automatically search of a rational cutting mode for milling non-rigid blanks with the specified quality parameters ICMTMTE IOP Conf. Series: Materials Science and Engineering 709(2020) 044069, IOP Publishing. https://doi.org/10.1088/1757-899X/709/4/044069

[8] Nguyen Khanh Toan, Mezin N. N. Study of the Efficiency of Ultrasonic Turning of HeatResistant Alloys with Tools from Mineral Ceramics. In: MATEC Web of Conferences 297, 01011(2019). https://doi.org/10.1051/matecconf/201929701011 